\title{
Early Detection and Management of Leakage after Sleeve Gastrectomy
}

\author{
Tarek M. Sherif, MD; Abd-Elrahman A.Sarhan, $M D$.
}

\author{
Department of General Surgery, Faculty of Medicine, Zagazig University.
}

Background: Staple line leakage is the most feared complication after laparoscopic sleeve gastrectomy (LSG). The aim of this study was to describe the rate of leakage, the clinical presentation, early diagnosis and different lines of treatment in patients who develop gastric leaks following $L S G$.

Patients and methods:This study is a retrospective review of 849 patients who underwent LSG in AL Ahli Hospital (Qatar), and AL Amiri Hospital (Kuwait), between May, 2008 and May, 2013. The collected data included patients' demographics, operative and perioperative parameters.

Results: 849 patients underwent LSG, 15 (1.8\%) with gastric leak were identified; 9 females $(60 \%)$ and 6 males (40\%) with a mean ageof 39.5 years and a mean body mass index (BMI) of $42.5 \mathrm{~kg} / \mathrm{m}^{2}$. Tachycardia was the most common presenting symptom of leakage (80\%), followed by fever (60\%), left upper abdominal pain (60\%) and left shoulder pain (60\%). Early detection of leakage (0-3 days) was found in 12 cases (80\%) and intermediate detection (4-14 days) was found in 3 cases (20\%). All leaks were found in the upper sleeve near the gastro esophageal junction (100\%). Re-operation was performed for 6 cases (40\%), percutaneous drainage for 6 cases (40\%), endoscopic placement of stents in 9 cases (60\%), and endoscopic insertion of clips in 3 cases (20\%). The median time for leakage closure was 25 days (10-42 days) and the overall leakage related mortality was 3 cases (20\%).

Conclusion: Staple line leakage is one of the complications following LSG (1.8\%). Early leakage is more common than intermediate and late leaks. Tachycardia is the most common presenting symptom. Most leaks occur in the upper part of the sleeve. The management should be planned based on the clinical evaluation and time of diagnosis of leakage.

Key words: Laparoscopic sleeve gastrectomy-complications-gastric leak-morbid obesity.

\section{Introduction:}

The prevalence of obesity has continued to increase in the last few decades. Currently it is estimated that there are greater than 1.7 billion overweight adults, and 300 million obese individuals worldwide. ${ }^{1}$ The prevalence of obesity in children has increased in the last 15 years from $2 \%$ to $10 \%$ in boys, and from $2 \%$ to $9 \%$ in girls. ${ }^{2}$ The ongoing increase in obesity may be associated with a multitude of factors including, but not limited to, genetics, diet habits, culture, and a general decline in exercise regimens.

Obesity is generally measured by body mass index (BMI) to estimate the degree of adiposity. Obesity is most commonly defined as a BMI $>30 \mathrm{~kg} / \mathrm{m}^{2}$, and morbid obesity is defined as a BMI $>40 \mathrm{~kg} / \mathrm{m}^{2}$. Some significant obesity related comorbidities include type 2 diabetes mellitus (T2DM), hypertension, gastro esophageal reflux disease, degenerative joint disease, depression, and cancers. ${ }^{3}$

Although many dietary therapies are available, patients seem to be most responsive to surgical intervention. Current surgical strategies consist of laparoscopic adjustable gastric banding (LAGB), laparoscopic sleeve gastrectomy (LSG), laparoscopic Roux-en-Y gastric bypass (LRYGB), and laparoscopic biliopancreatic diversion with duodenal 
switch (LBPD-DS). ${ }^{4}$

LSG is rapidly gaining momentum, both as a stand-alone and as a putative first-stage procedure in bariatric surgery since its introduction into the bariatric armamentarium. ${ }^{5,6}$ Its major advantages are its relative operative simplicity, lack of anastomosis, absence of malabsorptive component, and induction of a favorable hormonal change facilitating weight loss through restriction and appetite suppression. It has reported lower morbidity and mortality rates than (LRYGB) and (LBPD-DS), thereby making it more appealing 7,8 It also has been used as a revisional option for patients with failed bariatric procedures such as vertical banded gastroplasty, silastic ring vertical gastroplasty, LAGB, and previous sleeve gastrectomy. ${ }^{9-13}$

Its complications consist mainly of stapleline bleeding, stricture (usually located at the middle or distal portion of the residual stomach), and the most severe and dangerous complication being staple-line leaks. ${ }^{14}$ The reported gastric leak rates from the sleeve staple line are $(1.4-2.5 \%)$ for primary sleeve gastrectomies and (16-20\%) for re-operative surgery where a previous gastric operation has been performed. ${ }^{15-18}$

Gastric leakage occurs, most commonly, at the upper stable line near the gastro esophagealjunction. ${ }^{19-20}$ This complication if not identified and treated quickly and aggressively, may lead to abdominal sepsis, which might progress either to chronic gastric fistula or to multi-organ failure and patient demise. $^{21}$

\section{Patients and methods:}

From May, 2008 to May, 2013, 849 patients underwent laparoscopic sleeve gastrectomy(LSG) in two centers, the General Surgery Department of AL Ahli Hospital, Doha, Qatar and the General Surgery Department of AL Amiri Hospital, Kuwait. All patients had to agree with an informed consent after explanation of the procedure and its possible complications as well as the diet regimen during the post-operative period. Pre-operative investigations including ultrasound of the abdomen, coagulation profile, thyroid function tests, liver function tests, and serum cortisol level were routinely done for all cases. Prophylactic intravenous broad spectrum antibiotics with subcutaneous heparin, were given in all cases. Elastic stockings and pneumatic pump compression were applied during the procedure.

\section{LSG operation technique:}

The surgery was done in the French position in a 30 degrees reversed Trendlenburg's position. Pneumoperitonium was established to $15 \mathrm{~mm} \mathrm{Hg}$. Four trochars $(12 \mathrm{~mm})$ were used.The first trocar for placing the camera was inserted $15 \mathrm{~cm}$ distal to the xiphoid process. Another trocar was placed in the right lateral subcostal area for the liver retractor. Two trocars were located in the right and left upper quadrants. 36 French bougie was introduced by the anesthetist and adjusted close to the lesser curve till it reached the pylorus.

Starting $5 \mathrm{~cm}$ proximal to the pylorus, the greater curve of the stomach was freed from the gastro colic ligament and the short gastric vessels with the Harmonic ultrasound system up to the angle of His. To create the sleeve, the endo GIA stapler was fired along a line parallel to the lesser curve starting $5 \mathrm{~cm}$ proximal to the pylorus up to the cardia. The staple line was oversewn only along areas of bleeding. The excised portion of the stomach was extracted from the abdominal cavity by minimally enlarging the left upper quadrant incision and was subjected to histopathology examination. An intraoperative leakage test using methylene blue was done in all cases, and prophylactic tube drain was inserted along the staple line in all cases.

The surgical technique was the same in both centers, same bougie size (36-Fr), no buttressing materials were used, and over suturing the staple line was only applied over the bleeding points, but there was a slight variation between the two centers regarding the stapler manufacture choice and the staple height.

Gastrographin swallow was done routinely in all patients on the first and third 
postoperative days to check patency and to rule out leakage. Data was collected and analyzed retrospectively (age, sex, BMI, co morbidity, previous bariatric surgery, operative and post operative data, the presence or absence of leakage, the interval between surgery and diagnosis of leakage and the interval between diagnosis of leakage and its closure). Weekly follow up was done in the outpatient clinic for two month, where full clinical assessment and follow up fluoroscopy study were performed. Statistical analysis of the collected data was performed using SPSS software.

\section{Results:}

849 patients underwent LSG in both centers between May 2008 and May 2013. Among these 849 cases, we identified 15 (1.8\%) with gastric leakage. The 834 cases who underwent LSG and did not develop postoperative leak were considered as the control group, and the other 15 cases who developed post-operative leak were considered as the leak group.The leak group patients were 9 females $(60 \%)$ and 6 males (40\%), their mean age was 39.5 years and their mean body mass index (BMI) was $42.5 \mathrm{~kg} / \mathrm{m}^{2}$.

Twelve (12) patients in the leak group (80\%) had previous LAGB, while 84 patients in the control group (10\%) had previous LAGB. This difference in proportion is highly significant $(\mathrm{P}>0.005)$, implying an increased risk for leak in patients with previous bariatric surgery. Co-morbidities in the leak group included hypertension in 9 patients $(60 \%)$, dyslipidemia in 12 patients ( $80 \%$ ), obstructive sleep apnea in 6 patients (40\%) and type 2 diabetes mellitus in 6 patients $(40 \%)$. Patient demographics and preoperative data were demonstrated in Table (1).

Intra operative leakage test was done routinely for all cases using methylene blue dye but it did not detect the leakage in any of the cases.

The clinical presentation in the leak group included tachycardia in 12 cases $(80 \%)$, fever in 9 cases $(60 \%)$, left shoulder pain in 9 cases $(60 \%)$, left sided abdominal pain in 9 cases $(60 \%)$, and left sided chest pain in 6patients (40\%). Table (2).
An upper GI series using water soluble contrast (Gastrographin) was used in all patients on the first and third post operative days and diagnosed the leak in 12 cases ( $80 \%$ ), the remaining three cases were not diagnosed early and were discharged home on the fourth post operative day, then presented for follow up in the outpatient clinic ( 7 to 10 days after discharge) with left upper abdominal pain and tachycardia. Gastrographin study was repeated and proved the leak. Figures(1,2).

In all cases, the leakage was in the upper part of the sleeve near the gastro-esophageal junction (100\%). Re-operation was performed in 6 cases $(40 \%)$ where thorough laparoscopic washout and drainage of theabdomen with insertion of wide bore drains, and with direct suturing of the site of the leak were performed in three of these 6 cases where the tissues were healthy.

The other treatment options included percutaneous drainage under CT guide in 6 cases $(40 \%)$, endoscopic placement of stents in 9 cases $(60 \%)$, Figures $(3,4,5,6)$ andendoscopic clips insertion in 3 cases (20\%), Figure (7).

All cases had intravenous broad spectrum antibiotics, proton pump inhibitors (PPIs), prophylactic subcutaneous heparin, NPO, and total parenteral nutrition (TPN). The stents were removed after 4 weeks.

The median time for leak closure was 25 days (10-42 days). The overall leak related mortality was 3 patients $(20 \%)$ who died in the early post operative course, first one due to pulmonary embolism in spite of pre- and post-operative prophylactic heparin, the other two cases developed severe sepsis with multiorgan failure in spite of early diagnosis (third post operative day), immediate laparoscopic washout and insertion of wide bore drains. Table (3) shows the characters of the leak and the lines of its management.

\section{Discussion:}

Laparoscopic sleeve gastrectomy (LSG) is gaining popularity as a bariatric option with short and midterm results similar to those for laparoscopic Roux-en-Y gastric bypass but with lower morbidity and mortality 
rates. $^{22}$ The most common and important complications after LSG are: staple line bleeding, strictures, and the most severe, dangerous complication being staple line leakage. ${ }^{23}$

Staple line leakage after LSG ranges from $(0.7-5.3 \%)$ according to different studies, Table (4), and its clinical presentation ranges from mild micro leaks, that may cause peri sleeve abscess and chronic fistula, to an acute abdomen with sepsis, hemodynamic instability, multi organ failure, and rarely death(24). In our study, the percentage of leak was $1.8 \%$.

Baker suggests two main categories of leaks, classic ischemic leak that tend to appear between 5-6 days after surgery and mechanical leakthat tends to appear within two days after surgery. ${ }^{36}$ In our study, early leak was detected in 12 cases and intermediate leak was detected in 3 cases.

The cause of gastric leak is indicative of some abnormality or failure of normal healing process of tissue. There is a general agreement that local risk factors contributing to a leak are impaired suture line healing due to staple dehiscence, poor blood flow, and infection. These risk factors contribute to decrease in oxygen and subsequent ischemia to tissues. ${ }^{37}$

Atkins et al, ${ }^{38}$ demonstrated that the patients treated with the more restrictive (40-Fr) bougie experienced a significantly greater weight loss and more co-morbidities than those treated with a (50-Fr) bougie. In our study we used 36-Fr bougie for all cases.

The esophago-gastric junction has been reported as the usual site of leak after LSG. Particular attention should be paid to this area at the time of staple firing. It is important to use staples of an adequate height and avoid stapling the esophagus. ${ }^{39} \mathrm{We}$ noticed that the leak occurred in the upper part of the sleeve near gastro esophageal junction in all of our cases.

Routine or selective use of intraoperative diagnostic methods is controversial. Intraoperative endoscopy with air leak testing and trans- gastric dye injection have been used by some authors to detect a leak during the initial surgery. The rationale behind the routine use of these tests intraoperatively is to detect technical leaks (mechanical leaks) at a time when tissues are viable and most amenable to repair by re-stapling or suturing. A negative methylene blue test does not eliminate the possibility of a leak. ${ }^{40}$ In our study, we routinely used intra operative methylene blue leak test which did not detect any leak in all of the cases, while 15 cases developed leakage later on and were diagnosed by gastrographin fluoroscopy study.

The clinical presentation of leak can vary widely between totally asymptomatic patients diagnosed with routine imaging study (gastrographin) postoperatively 40 to the symptoms and signs of septic shock including fever, abdominal pain, peritonitis, leukocytosis, tachycardia and hypotension. ${ }^{41}$

Dakwar et al stated that fever is the most important clinical factor in the diagnosis of gastric leak post sleeve gastrectomy. ${ }^{23}$ Others stated that tachycardia is the earliest and most important and constant clinical finding indicating presence of leak, and tachycardia $>120$ beats/minute is a powerful indicator of leak and systemic compromise. ${ }^{19}$

Early leaks usually present with sudden abdominal pain, accompanied with fever and tachycardia in most cases, while late leaks tend to present with insidious abdominal pain commonly associated with fever. ${ }^{42} \mathrm{We}$ observed that the most common presentation was tachycardia, followed by fever, left upper abdominal pain andleft shoulder pain.

Routine gastrographin swallow test 24-72 hours post operatively is still an area of large debate. While Wahby et al, have shown its inability to detect post operative leak, they still recommend it to be done routinely, especially that it can detect other complications like strictures and anatomical consequences of the sleeve. ${ }^{40}$

CT scan of the abdomen with intravenous and oral water soluble contrast is considered to be the best non-invasive modality for detection and confirmation of a gastric leak. ${ }^{43}$ This superiority of CT scan is questioned by some investigators, lying on the fact 


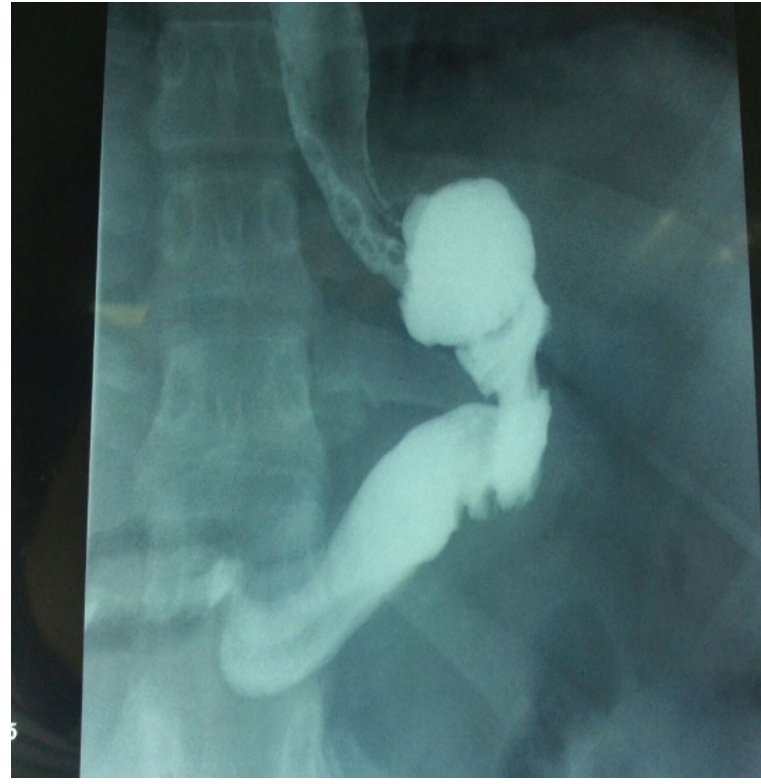

Figure (1): Normal postoperative fluoroscopy study.

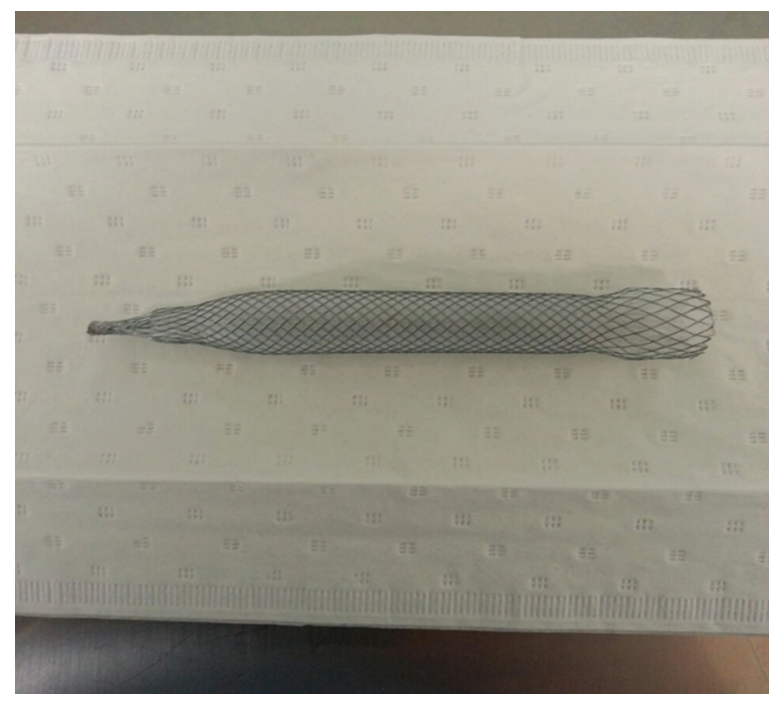

Figure (3): Stent before insertion.

that obesity and large body dimensions $(\mathrm{BMI}<50)$ produce artifacts that reduce the image quality and also produce technical difficulties that may overcome the ability of the framework to support and thus they recommend gastrographin swallow instead. ${ }^{29}$ In our series we performed routine gastrographin swallow for all cases on the first and third post operative days.

The management of leak following LSG imposes a lot of controversies and difficulties in the adoption of a standard algorithm. Based

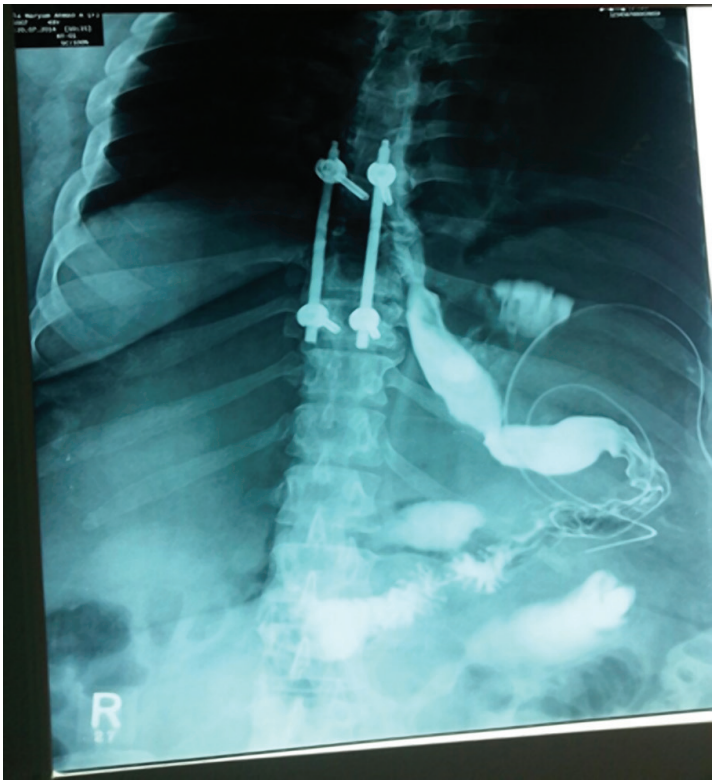

Figure (2): Post operative fluoroscopy study showing leakage in the upper part of the sleeve. This patient had previous spine fixation with metal screws.

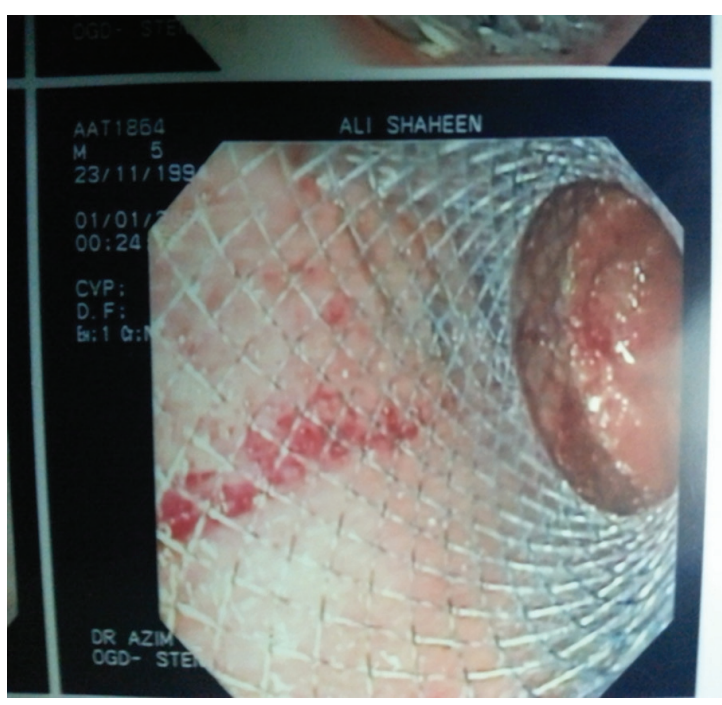

Figure (4): Endoscopic view of the stent after insertion.

on the first international summit for sleeve gastrectomy, the treatment may include early oversewing and drainage (open or laparoscopic), endoscopic clipping, stenting or using fibrin glue, sometimes the use of Roux loop or totalgastrectomy as the last resort. ${ }^{44}$ In unstable patients upon presentation, prompt surgical intervention by laparoscopic or open means is recommended for washout and drainage, at least, that may be coupled with debridement and suturing of the orifice if the condition of the patient and the tissues, 


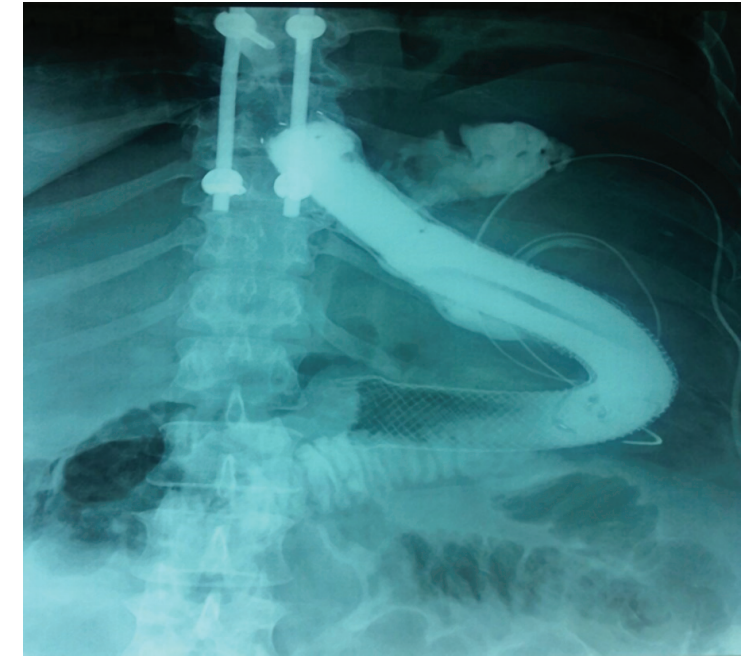

Figure (5): Post stent insertion fluoroscopy study showing distal migration of the stent with persistent leakage in the upper part.

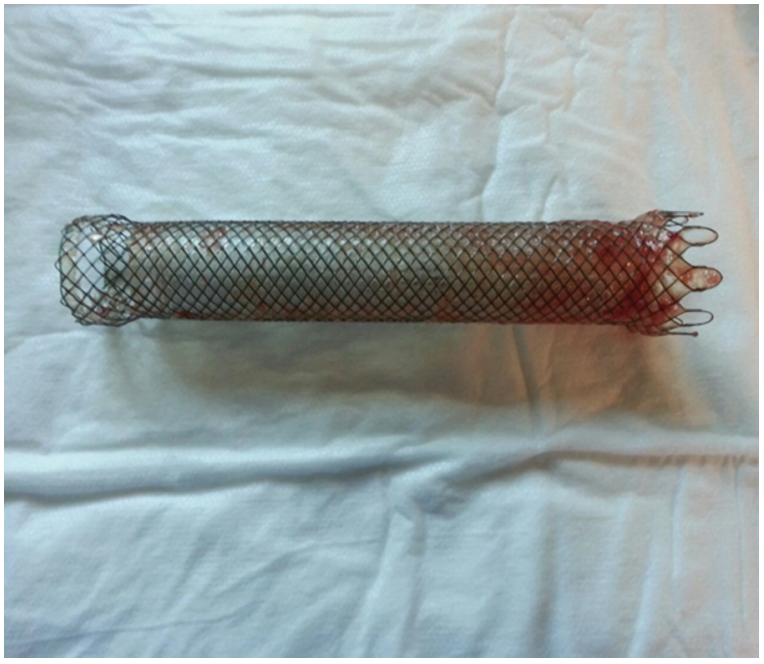

Figure (6): Stent after removal.

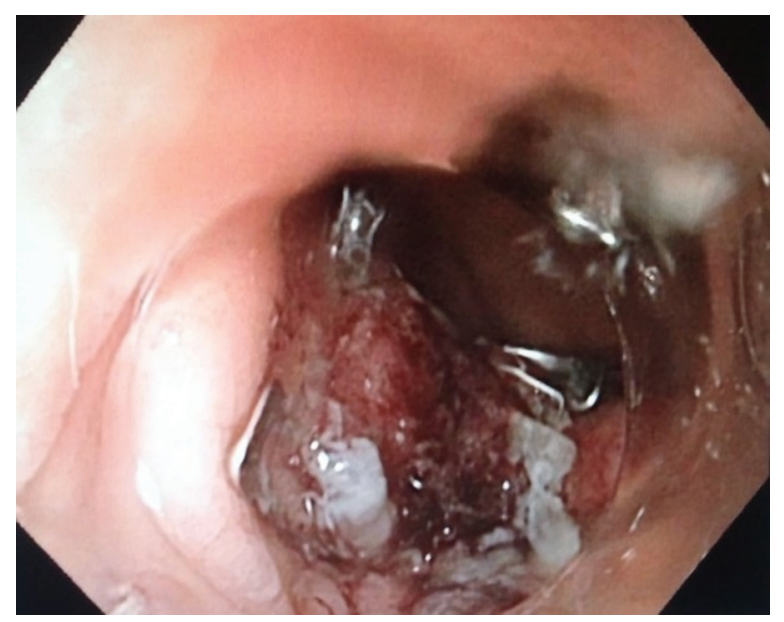

Figure (7): Endoscopic clip insertion.

Table (1): patient demographics and preoperative data.

\begin{tabular}{|l|l|l|l|}
\hline \multicolumn{1}{|c|}{ Parameters } & Control group (n=834) & Leak group $(\mathbf{n}=\mathbf{1 5})$ & p value \\
\hline Mean age (years) & 39.8 & 39.5 & $>0.05$ \\
\hline Mean BMI (Kg/M2) & 42.1 & 42.5 & $>0.05$ \\
\hline Males (\%) & $34 \%$ & $40 \%$ & $>0.05$ \\
\hline Females (\%) & $66 \%$ & $60 \%$ & $>0.05$ \\
\hline Hypertension (\%) & $52 \%$ & $60 \%$ & $>0.05$ \\
\hline Dyslipidemia (\%) & $68 \%$ & $80 \%$ & $>0.05$ \\
\hline Sleep apnea (\%) & $28 \%$ & $40 \%$ & $>0.05$ \\
\hline Type 2 diabetes (\%) & $27 \%$ & $40 \%$ & $>0.05$ \\
\hline Previous LAGB (\%) & $10 \%$ & $80 \%$ & $<0.005$ \\
\hline
\end{tabular}

and the skills and experience of the surgeon permit. ${ }^{40}$ This immediate surgical intervention in early leaks showed better outcome than the more conservative approach. While the adoption of a more conservative approach for intermediate and late leaks in clinically stable 
Table (2): Clinical presentation in the leak group.

\begin{tabular}{|l|l|l|}
\hline Symptoms and signs & Number of cases & Percentage \\
\hline Tachycardia & 12 & $80 \%$ \\
\hline Fever & 9 & $60 \%$ \\
\hline Left shoulder pain & 9 & $60 \%$ \\
\hline Left abdominal pain & 9 & $60 \%$ \\
\hline Left chest pain & 6 & $40 \%$ \\
\hline
\end{tabular}

Table (3): Characters of the leak and lines of management.

\begin{tabular}{|l|l|l|}
\hline \multicolumn{1}{|c|}{ Character } & Number & Percentage \\
\hline Site (upper part) & 15 & $100 \%$ \\
\hline Early detection (0-3 days) & 12 & $80 \%$ \\
\hline Intermediate detection (4-14 days) & 3 & $20 \%$ \\
\hline Laparoscopic drainage & 6 & $40 \%$ \\
\hline laparoscopic suturing & 3 & $20 \%$ \\
\hline Percutaneous drainage & 6 & $40 \%$ \\
\hline Endoscopic clip insertion & 3 & $20 \%$ \\
\hline Endoscopic stents & 9 & $60 \%$ \\
\hline
\end{tabular}

Table (4): Percentage of staple line leaks after LSG in different studies.

\begin{tabular}{|c|c|c|c|c|}
\hline Authors & $\begin{array}{c}\text { Number of } \\
\text { patients }\end{array}$ & $\begin{array}{c}\text { Number of } \\
\text { leaks }\end{array}$ & $\begin{array}{c}\text { Percentage of } \\
\text { leaks }\end{array}$ & Years \\
\hline Lacy et $\mathrm{al}^{26}$ & 294 & 11 & $4 \%$ & 2010 \\
\hline Daskalakis et al 25 & 230 & 10 & $4.3 \%$ & 2011 \\
\hline Bellanger and Greenway ${ }^{27}$ & 529 & 0 & $0 \%$ & 2011 \\
\hline Simon et al 28 & 139 & 5 & $3.6 \%$ & 2011 \\
\hline Jurowich et al 29 & 45 & 4 & $8-9 \%$ & 2011 \\
\hline Gagniere et al ${ }^{30}$ & 102 & 7 & $6.9 \%$ & 2011 \\
\hline Albanopoulos et al ${ }^{31}$ & 353 & 12 & $3.4 \%$ & 2011 \\
\hline Weiner et al ${ }^{32}$ & 686 & 12 & $1.7 \%$ & 2013 \\
\hline Sakran et al 22 & 2834 & 44 & $1.5 \%$ & 2013 \\
\hline Albanopoulos et al ${ }^{33}$ & 90 & 2 & $2.2 \%$ & 2012 \\
\hline Gill et al ${ }^{34}$ & 116 & 0 & $0 \%$ & 2012 \\
\hline Spyropoulos et al 35 & 208 & 12 & $5.8 \%$ & 2012 \\
\hline
\end{tabular}

patients is more reasonable with adequate hydration, PPIs, NPO, parenteral nutrition, broad spectrum antibiotics, and percutaneous drainage of any collection. ${ }^{45}$ Weekly follow up by gastrographin swallow should be done, and if the leak does not heal after 2 weeks, endoscopic management can be considered with wide range of success. 46,47
Over the scope clips (OTSC) have more promising results, but they are limited for very small mucosal defects and micro perforations, and are inefficacious in inflammatory or edematous mucosa, and demanding technical skills. $^{48}$ Sealant materials including fibrin glue and cyanoacrylates were used by some authors. ${ }^{49}$ Nguyen et al,used self expanding 
stents with a success rate of $100 \% .{ }^{47}$

A complete endoscopic approach was also suggested by Bege et al, ${ }^{49}$ without the need for any surgical intervention that consists of three stages of endoscopic treatment: Washout and drainage using natural orifices transluminal endoscopic surgery (NOTES), diversion using a stent, closure with glue or clips.

In our study, 12 cases were diagnosed early and the remaining 3 cases were diagnosed later during routine follow up in the outpatient clinic. Re-operation was performed in 6 cases in the form of laparoscopic washout and insertion of wide bore drain, laparoscopic suturing was done in 3 of them, 6 cases required $\mathrm{CT}$ guided drainage. Endoscopic clip insertion was done in 3 cases, and endoscopic placement of stent was done in 9 cases. The median time for leak closure was 25 days (10-42 days).

\section{Conclusions:}

The apparent simplicity of LSG hides a number of complications; staple line leakage is one of them (1.8\%). Early leak is more common than intermediate and late leaks. Tachycardia is the most common presenting symptom followed by fever, left upper abdominal pain and left shoulder pain. All leaks are detected in the upper part of the sleeve near gastro esophageal junction. Its management is variable with no standard algorithm to follow, but it should be planned based on the clinical evaluation and time of diagnosis. The absence of clear approach and guidelines for the management of gastric leaks, emphasizes the importance of prophylaxis.

\section{Reference:}

1- Ahima RS: Digging deeper into obesity. The Journal of Clinical Investigation 2011; 121(6): 2076-2079.

2- Canning PM, Courage ML, Frizzel LM: Prevalence of overweight and obesity in a provincial population of Canadian preschool children. CMAJ 2004; 181: 240-242.

3- Karmali S, Schauer P, Birch D, Sharma AM, Sherman V: Laparoscopic sleeve gastrectomy: An innovative new tool in the battle against the obesity epidemic in Canada. Can J Surg 2010; 53 (2): 126-132.

4- Kopelman PG: Obesity as a medical problem. Nature 2000; 404: 635-643.

5- Baltasar A, Serra C, Perez N, Bou R, Bengochea M, Ferri L: Laparoscopic sleeve gastrectomy: A multipurpose bariatric operation. Obes Surg 2005; 15: 1124-1128.

6- CottamD, Qureshi FG, Mattar SG, Sharma S, Holover S, Bonanomi G, et al: Laparoscopic sleeve gastrectomy as an initial weight loss procedure for high-risk patients with morbid obesity. Surg Endosc 2006; 20: 859-863.

7- Arias E, Martinez PR, Ka Ming LV, Szomstein S, Rosenthal RJ: Midterm follow-up after sleeve gastrectomy as a final approach for morbid obesity. Obes Surg 2009; 19: 544-548.

8- Moy J, Pomp A, Dakin G, Parikh M, Ganger M: Laparoscopic sleeve gastrectomy for morbid obesity. Am J Surg 2008; 196: 56-59.

9- Baltasar A, Serra C, Perez N, Bou R, Bengochea M: Re-sleeve gastrectomy. Obes Surg 2006; 16: 1535-1538.

10- DapriG, Cadiere GB, Himpens J: Feasibility and technique of laparoscopic conversion of adjustable gastric banding to sleeve gastrectomy. Surg Obes Relat Dis 2009; 5: $72-76$.

11- ElazaryR, Hazzan D, Appelbaum L, Rivkind Al, Keidar A: Feasibility of sleeve gastrectomy as a revision operation for failed silastic ring vertical gastroplasty. Obes Surg 2009; 19: 645-649.

12- Foletto M, Prevedello L, Bernante P, Luca B, Vettor R, Pesenti FF, et al: Sleeve gastrectomy as revisional procedure for failed gastric banding or gastroplasty. Surg Obes Relat Dis 2009; 6: 146-151.

13- Goitein D, Feigin A, Segal-Lieberman G, Goitein O, Papa MZ, Zippel D: Laparoscopic sleeve gastrectomy as a revisional option after gastric band failure. Surg Endosc 2011; 25: 2626-2630.

14- Csendes A, Braghetto I, Leon P, Burgos AM: Management of leaks after laparoscopic sleeve gastrectomy in patients with obesity. Journal of Gastrointestinal Surgery 2010; 14(9): 1343-1348.

15- Lee CM, Cirangle PT,Jossart GH: Vertical gastrectomy for morbid obesity in 216 patients: report of two-year results. Surg Endosc 2007; 21(10): 1810-1816.

16- 16- Nocca D, Krawczykowsky D, Bomans B, Noel P, Picot MC, Blanc PM, et al:A prospective multicenter study of 163 sleeve 
gastrectomies: results at 1 and 2 years. Obes Surg 2008; 18 (5): 560-565.

17- Fuks D, Verhaeghe P, Brehant O, Sabbagh C, Dumont F, Riboulot M, et al: Results of laparoscopic sleeve gastrectomy: A prospective study in 135 patients with morbid obesity. Surgery 2009; 145(1): 106-113.

18- Himpens J, Dapri G, and Cadiere GB: A prospective randomized study between laparoscopic gastric banding and laparoscopic isolated sleeve gastrectomy: Results after 1 and 3 years. Obes Surg 2006; 16(11): 1450-1456.

19- Burgos AM, Braghetto I, Csendes A, Maluenda F, Korn O, Yarmuch J, et al: Gastric leak after laparoscopic sleeve gastrectomy for obesity. Obes Surg 2009; 19: 1672-1677.

20- Deitel M, Crosby RD, Gagner M: The first international consensus summit for sleeve gastrectomy (SG), New York, October 2527. Obes Surg 2008; 18: 487-496.

21- Gagner M, Deitel M, Kalberer TL, Erickson AL, Crosby RD: The second international consensus summit for sleeve gastrectomy, March 19-21. Surg Obes Relat Dis 2009; 5: 476-485.

22- Sakran N, Goitein D, Raziel A, Keidar A, Beglaibter N, Grinbaum R, et al: Gastric leaks after sleeve gastrectomy: A multicenter experience with 2834 patients. Surg Endosc 2013; 27: 240-245.

23- DakwarA, Assalia A, Khamaysi I, Kluger Y, Mahajna A: Late complications of laparoscopic sleeve gastrectomy. Case Rep Gastroint Med 2013; 136: 153-157.

24- Marquez MF, Ayza MF, Lozano RB, Morales M, Diez J, Poujoulet RB: Gastric leak after laparoscopic sleeve gastrectomy. Obes Surg 2010; 20: 1306-1311.

25- Daskalakis M, Berdan Y, Theodoridou $S$, Weigand $G$, Weiner RA: Impact of surgeon experience and bauttress material on postoperative complications after laparoscopic sleeve gastrectomy. Surg Endosc 2011; 25: 88-97.

26- Lacy A, Ibarzabal A, Pando E, Adelsdorfer C, Delitala A, Corcelles R, et al: Revisional surgery after sleeve gastrectomy. Surg Laparosc Endosc Percutan Tech 2010; 20: 351-356.

27- Bellanger DE, Greenway FL: Laparoscopic sleeve gastrectomy, 529 cases without a leak: Short-term results and technical considerations. Obes Surg 2011;21: 146-150.

28- Simon TE, Scott JA, Brockmeyer JR, Rice RC, Frizzi JD, Husain FA, et al: Comparison of staple-line leakage and hemorrhage in patients undergoing laparoscopic sleeve gastrectomy with or without Seamguard. $\mathrm{Am}$ J Surg 2011; 77(12): 1665-1668.

29- Jurowich C, Thalheimer A, Seyfried F, Fein $\mathrm{M}$, Bender G, Germer CT, et al: Gastric leakage after sleeve gastrectomy-clinical presentation and therapeutic options. Langenbecks Arch Surg 2011; 396(7): 981-987.

30- Gagniere J, Slim K, Launay-Savary MV, Raspado O, Flamein R, Chipponi J: Previous gastric banding increases morbidity and gastric leaks after laparoscopic sleeve gastrectomy for obesity. J Visc Surg 2011; 148(3): 205-209.

31- Albanopoulos K, Alivezos L, Linardoutsos D, Menenakos E, Stamou K, Vlachos K, et al: Routine abdominal drains after laparoscopic sleeve gastrectomy: A retrospective review of 353 patients. Obes Surg 2011; 21(6): 687-691.

32- Weiner RA, El-Sayes IA, Theodoridou S, Weiner SR, Scheffel O: Early postoperative complications: Incidence, management, and impact of length of hospital stay. A retrospective comparison between laparoscopic gastric bypass and sleeve gastrectomy. Obes Surg 2013; 23(12): 2004-2012.

33- Albanopoulos K, Alivezos L, Flessas J, Menenakos E, Stamou KM, Papailiou J, et al: Reinforcing the staple line during laparoscopic sleeve gastrectomy: prospective randomized clinical study comparing two different techniques. Preliminary Results. Obes Surg 2012; 22(1): 42-46.

34- Gill RS, Switzer N, Driedger M, Shi X, Vizhul A, Sharma AM, et al: Laparoscopic sleeve gastrectomy with staple line buttress reinforcement in 116 consecutive morbidly obese patients. Obes Surg 2012; 22(4): 560-564.

35- Spyropoulos C, Argentou MI, Petsas T, Thomopoulos K, Kehagias I, Kalfarentzos F: Management of gastrointestinal leaks after surgery for clinically severe obesity. Surg Obes Relat Dis 2012; 8(5): 609-615.

36- Baker RS, Foote J, Kemmeter P, Brady R, Vroegop T, Serveld M: The science of stapling and leaks. Obes Surg 2004; 14(10): 1290-1298.

37- Shimizu H, Annaberdyev S, Motamarry I, Kroh M, Schauer PR, Brethauer SA: Revisional bariatric surgery for unsuccessful weight loss and complications. Obes Surg 
2013; 23: 1766-1773.

38- Atkins ER, Preen DB, Jarman C, Cohen LD: Improved obesity reduction and co-morbidity resolution in patients treated with $40-\mathrm{Fr}$ bougie versus $50-\mathrm{Fr}$ bougie, 4 years after laparoscopic sleeve gastrectomy. Analysis of 294 patients. Obes Surg 2012; 22: 97-104.

39- Rosenthal RJ, Diaz AA, Arvidsson D, Baker RS, Basso N, Bellanger D, et al: International Sleeve Gastrectomy Expert Panel Consensus Statement: best practice guidelines based on experience of $<12000$ cases. Surg Obes Relat Dis 2012; 8: 8-19.

40- Wahby M, Salama AF, Elezaby AF, Belgrami F, AbdEllatif ME. El-Kaffas HF, et al: Is routine postoperative gastrografin study needed after Laparoscopic sleeve gastrectomy? Experience of 712 cases. Obes Surg 2013; 23: 1711-1717.

41- Welsch T, Von Frankenberg M, Schmidt J, Buchler MW: Diagnosis and definition of anastomotic leakage from the surgeon's perspective. Der Chirurg 2011; 82: 48-55.

42- Stamou KM, Menenakos E, Dardamanis D, Arabatzi C, Alvizos L, Albanopoulos K, et al: Prospective comparative study of the efficacy of staple-line reinforcement in laparoscopic sleeve gastrectomy. Surg Endosc 2011; 25: 3526-3530.

43- Aurora AR, Khaitan L, Saber AA: Sleeve gastrectomy and the risk of leak: A systematic analysis of 4888 patients. Surg Endosc 2012; 26: $1509-1515$.
44- De Aretxabala X, Leon J, Wiedmaier G, Turu I, Ovalle C, Maluenda F, et al: Gastric leak after sleeve gastrectomy: Analysis of its management. Obes Surg 2011; 21: 1232-1237.

45- Parikh M, Issa R, McCrillis A, Saunders JK, Ude-Welcome A, Gagner M: Surgical strategies that may decrease leak after laparoscopic sleeve gastrectomy: A systematic review and meta-analysis of 9991 cases. Ann Surg 2013; 257: 231-237.

46- Canio M, Blanchi S, Repici A, Bastardini $\mathrm{R}$, Marinari GM: Use of an over-the-scope clip for endoscopic sealing of a gastric fistula after sleeve gastrectomy. Endoscopy 2010; 42(2): 71-72.

47- Nguyen N, Nguyen X,Dholakia C: The use of endoscopic stent in management of leaks after sleeve gastrectomy. Obes Surg 2010; 20: 1289-1292.

48- Mennigen R, Colombo-Benkmann M, Senninger N, Laukoetter M: Endoscopic closure of postoperative gastrointestinal leakages and fistulas with the Over-the-Scope Clip (OTSC). J Gastrointest Surg 2013; 17: 1058-1065.

49- BegeT, Emungania O, Vitton V, Ah-Soune P, Nocca D, Noel P, et al: An endoscopic strategy for management of anastomotic complications from bariatric surgery: A prospective study. Gastrointest Endosc 2011; 73: $238-244$ 